\title{
Controlling Flow Instability in Straight Spur Gear Forging Using Numerical Simulation and Response Surface Method
}

\author{
Zhao-Yang $\mathrm{Jin}^{1} \cdot$ Nan-Nan $\mathrm{Li}^{1} \cdot$ Kai Yan $^{1} \cdot \mathrm{Jing}$ Xin $\mathrm{Chen}^{1} \cdot$ Dong-Lai Wei $^{2} \cdot$ Zhen-Shan $\mathrm{Cui}^{3}$
}

Received: 22 July 2017/Revised: 30 August 2017/Published online: 2 November 2017

(C) The Chinese Society for Metals and Springer-Verlag GmbH Germany 2017

\begin{abstract}
Workability domain without the onset of flow instability was developed by numerical simulation and response surface method (RSM) for complex-shaped straight spur gear forging. The processing map of AZ31B alloys was calculated from flow stress curves and then integrated with the finite element model to simulate the distribution of flow instability in the straight spur gear undergoing isothermal forging process. Occurrence of flow instability depends on forging temperature, punch velocity and billet reduction. Taking forging temperature and punch velocity as design variables, while billet reduction as response variable, RSM of workability domain was established. Analysis of variance indicates that forging temperature is the most significant factor determining the appearance of flow instability in the forged gear. Flow instability is easier to take place at lower temperatures of 250 and $300{ }^{\circ} \mathrm{C}$ in the early stage of forging but at higher temperatures of 350 and $400{ }^{\circ} \mathrm{C}$ in the later stage of forging, which is attributed to different deformation mechanisms and dynamic recrystallization behaviors at different temperatures or deformation levels. Meanwhile, increasing punch velocity further reduces the workability of the forged gear. Four different processing paths were chosen to carry out the gear forging trials. Visual observations and metallographic examinations demonstrate that the developed workability domain contributes to optimization of forging parameters.
\end{abstract}

KEY WORDS: Processing map; Finite element method; Response surface method; Straight spur gear; Magnesium alloy

\section{Introduction}

Straight spur gears, as one of typical transmission parts, have been widely used in automobiles and other machineries. Forging gears have a number of advantages, such as high material utilization, high production efficiency

Available online at http://link.springer.com/journal/40195

Zhao-Yang Jin

zyjin@yzu.edu.cn

1 School of Mechanical Engineering, Yangzhou University, Yangzhou 225127, China

2 School of Mechanical Engineering, Shanghai Dianji University, Shanghai 201306, China

3 National Die and Mold CAD Engineering Research Center, Shanghai Jiao Tong University, Shanghai 200030, China and low manufacture cost. Furthermore, continuous, dense and uniformly distributed streamlines inside forging gear, especially along the tooth profile, significantly enhance its service performance. Forging gears of magnesium alloys possess the advantages of lightweight, excellent damping and heat-dissipating properties, which can be used in aerospace, automobile and electronic industry. Technical challenges in forging straight spur gear include high forming load, poor tooth filling, demolding difficulty due to no draft angle, and flow instability defects. In order to avoid flow instability defects, such as flow localization, voids and cracking, many researchers applied processing map to investigate workability of material, i.e., deformation capacity of material before being broken during bulk forming. Prasad et al. [1] developed a processing map (PM) based on dynamic materials model (DMM). This developed PM not only indicate the regime of flow instability, 
but also reflect microstructural evolution mechanisms in different regimes. So far, PM has been widely used in optimizing deformation parameters for various materials, such as composites [2, 3], magnesium alloys [4, 5], aluminum alloys [6], steels [7, 8], titanium alloys $[9,10]$ and nickel alloys $[11,12]$.

Workability of materials includes intrinsic workability and state-of-stress (SOS) workability [13]. The intrinsic workability is dependent on chemical composition, initial microstructure, temperature, strain rate and strain. The SOS workability is related to the specific forging shape and forming technology. For magnesium alloys, Anbuselvan and Ramanathan [14] studied the workability of as-cast and as-extruded ZE41A alloy using PM. Compared to as-cast alloy, the as-extruded alloy possesses superior workability due to grain refinement. Zhong et al. [15] developed the PM of AZ31B alloy prepared by disintegrated metal deposition followed by hot extrusion, based on which the optimal processing parameters were determined. Zhu et al. [16] established the $\mathrm{PM}$ of $\mathrm{Mg}-8 \mathrm{Zn}-1 \mathrm{Al}-0.5 \mathrm{Cu}-0.5 \mathrm{Mn}$ alloys and concluded that the alloys have excellent workability in the temperature range of $318-350{ }^{\circ} \mathrm{C}$ and the strain rate range of $0.001-0.05 \mathrm{~s}^{-1}$. Rao et al. [17] built the processing map of $\mathrm{Mg}-3 \mathrm{Sn}-2 \mathrm{Ca}-0.4 \mathrm{Al}-0.4 \mathrm{Si}$ alloys for optimizing processing technology of a cup-shape forging. Zhou et al. [18] developed the processing map of $\mathrm{Mg}-\mathrm{Gd}-$ $\mathrm{Y}-\mathrm{Nb}-\mathrm{Zr}$ alloy, which shows that flow instability occurred mainly at the strain rate range of $0.3-0.5 \mathrm{~s}^{-1}$, and the optimal processing domain is at the temperature range of $703-765 \mathrm{~K}$ with the strain rate range of $0.01-0.1 \mathrm{~s}^{-1}$. The above studies mainly focused on the intrinsic workability of material. Liu et al. [19] developed an FE model integrated with PM to investigate both the intrinsic workability and the SOS workability of AZ31B alloys. They successfully predicted the adiabatic shear band, which is theoretically formed diagonally in cylindrical compressed specimens. In this paper, workability domain where no flow instability occurs for the forging of straight spur gear was constructed using numerical simulation (by coupling PM with FE model) and response surface method (RSM). This technology may contribute to the optimization of forging parameters and significant reduction in time-consuming and high-cost trial-and-error testing.

RSM is a combination of mathematical and statistical techniques, which is used to approximate the real unknown function, where response variables of interest are influenced by multiple design variables. This method aims at determining optimal design variables or specific domains, where design requirement can be satisfied. It has important applications in billet design [20], processing technology optimization [21] and microstructure optimization $[22,23]$. In this paper, a new method that integrates FEM, PM and RSM was proposed to control flow instability and optimize processing parameters of complex-shaped straight spur gear. The PM of AZ31B alloys was firstly integrated with FEM to simulate the variation of minimum instability parameter during forging. Then, critical value of billet reduction corresponding to onset of flow instability was determined at each chosen deformation temperature and punch velocity. After establishment of the workability domain using RSM, forging trials were carried out to validate the reliability of the proposed method.

\section{Coupling FEM with Processing Map}

\subsection{Gleeble Thermo-Mechanical Testing}

To construct the processing map and the finite element model, hot compression tests were conducted on a Gleeble 1500 thermo-mechanical simulator to obtain the flow stress curves. A commercial AZ31B magnesium alloy containing $2.8 \% \mathrm{Al}$ and $1.26 \% \mathrm{Zn}$ (in wt $\%$ ) was applied in this work. Cylindrical specimens with a diameter of $10 \mathrm{~mm}$ and a height of $15 \mathrm{~mm}$ were heated to temperatures of $250-400{ }^{\circ} \mathrm{C}$ with a heating rate of $5{ }^{\circ} \mathrm{C} / \mathrm{s}$. After holding for $5 \mathrm{~min}$ to eliminate temperature gradient, all specimens were deformed to a true strain of 0.9 at strain rate of 0.001-1 s $\mathrm{s}^{-1}$. The true stress-strain curves of AZ31B alloy are presented in Fig. 1.

\subsection{Processing Map}

Processing map developed by Prasad et al. [1] is a superimposition of the instability map on the power dissipation map in the space of deforming temperature and strain rate. It can describe the microstructure evolution mechanism of material under different deformation conditions. According to the dynamic materials model, the power dissipated by the workpiece undergoing hot deformation (denoted as $P$ ) includes two parts: (1) $G$ content, representing power dissipated by plastic deformation; (2) $J$ co-content, representing power dissipated by microstructure evolution. Both parts are associated with the constitutive relationship of materials, which is given by

$P=\sigma \dot{\varepsilon}=G+J=\int_{0}^{\dot{\varepsilon}} \sigma \mathrm{d} \dot{\varepsilon}+\int_{0}^{\sigma} \dot{\varepsilon} \mathrm{d} \sigma$

where $\sigma$ is the flow stress and $\dot{\varepsilon}$ is the strain rate. If the constitutive equation satisfies the DMM assumption as

$\sigma=k \cdot \dot{\varepsilon}^{m}$

where $k$ is the material constant, $m$ is the strain rate sensitivity, which is a function of temperature and strain rate for alloys with complex chemical composition. For given temperature and strain, $m$ is related to $G$ and $J$ as 

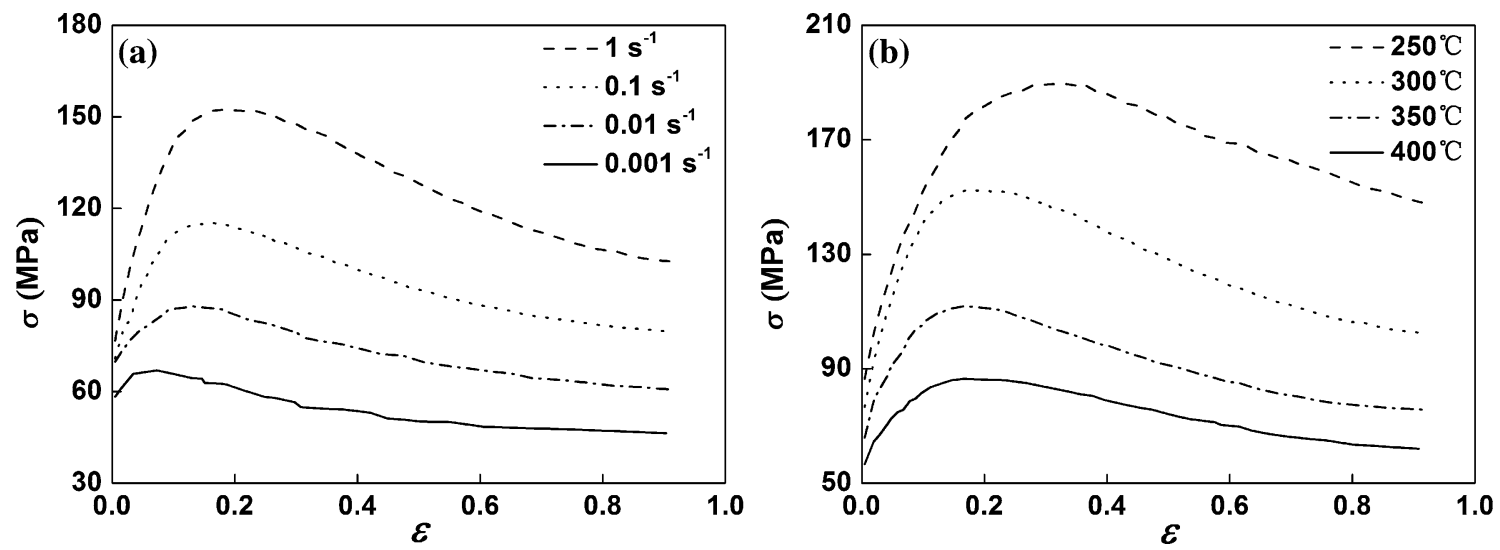

Fig. 1 True stress-strain curves of AZ31B alloy during hot compression under conditions of a $300{ }^{\circ} \mathrm{C}, \mathbf{b ~}^{1} \mathrm{~s}^{-1}$

$m=\left(\frac{\partial J}{\partial G}\right)_{T, \varepsilon}=\left(\frac{\dot{\varepsilon} \mathrm{d} \sigma}{\sigma \mathrm{d} \dot{\varepsilon}}\right)_{T, \varepsilon}=\left(\frac{\partial(\ln \sigma)}{\partial(\ln \dot{\varepsilon})}\right)_{T, \varepsilon}$.

The efficiency of power dissipation $(\eta)$ is defined as the ratio of $J$ co-content to its maximal value $J_{\max }$. If the material is an ideal linear power dissipater, i.e., $m=1, J$ co-content reaches its maximal value as $J_{\max }=\sigma \dot{\varepsilon} / 2$. Substituting $J_{\max }$ and Eq. (2) into the definition of $\eta$, it obtains

$\eta=\frac{J}{J \max }=\frac{\int_{0}^{\sigma} \dot{\varepsilon} \mathrm{d} \sigma}{\sigma \dot{\varepsilon} / 2}=\frac{2 m}{m+1}$.

Ziegler developed the instability criterion according to the extremism principles of irreversible thermodynamics [24]. This criterion for the onset of flow instability is expressed by the instability parameter of $\xi(\dot{\varepsilon})$ as [25]

$\xi(\dot{\varepsilon})=\frac{\partial \ln \left(\frac{m}{m+1}\right)}{\partial \ln \dot{\varepsilon}}+m<0$.

Obviously, both $\eta$ and $\xi(\dot{\varepsilon})$ are functions of temperature and strain rate. The power dissipation map describes the three-dimensional (3D) variation of $\eta$ as a function of temperature and strain rate. It is generally viewed as a twodimensional iso-efficiency contour map. Generally speaking, the hot workability of material is better at higher value of $\eta$. The instability map represents the variation of $\xi(\dot{\varepsilon})$ with temperature and strain rate. The instability area is the region where $\xi(\dot{\varepsilon})$ is negative, which should be avoided in hot working. If hot deformation is performed in this area, flow instability defects, such as local plastic deformation, adiabatic shear bands and wedge cracking, are observed in the workpiece. Processing map contributes to determine the temperature-strain rate window for hot deformation from the point of the intrinsic workability.

Before the construction of the processing map, whether or not the flow stress curves of AZ31B alloy meet the
DMM assumption should be examined. The plot of $\lg \sigma-$ $\lg \dot{\varepsilon}$ as shown in Fig. 2 indicates that $\lg \sigma$ and $\lg \dot{\varepsilon}$ follows the power law relationship illustrated in Eq. (2) at given strains and deformation temperatures. Therefore, it is reasonable to construct the processing map of AZ31B alloy based on the DDM assumption.

According to Eq. (3), values of strain rate sensitivity were obtained from the slope of $\lg \sigma-\lg \dot{\varepsilon}$ plot at each given strain and temperature. Then the efficiency of power dissipation and the instability parameter was calculated according to Eqs. (4) and (5). The processing map of AZ31B alloys was obtained, and its two-dimensional (2D) contour maps at different strains are shown in Fig. 3. The numbers near the contour lines represent the value of $\eta$ in the form of percentage, light gray areas represent peak efficiency regime, and dark gray areas denote instability regime.

Obviously, the processing map of AZ31B is strain dependent where distributions of peak efficiency and instability parameter vary with strain. Similar phenomena were reported in AZ80 alloy [26] and AA7050 alloy [27]. The reason lies in the fact that flow stress curves of AZ31B alloys exhibit typical dynamic recrystallization (DRX) characteristics. The curves vary with strain significantly and can be expressed as a function of temperature, strain rate and strain.

\subsection{FEM for Straight Spur Gear Forging Coupled with PMs}

\subsubsection{Die Structure Design}

Taking a customized straight spur gear for automobile electro-motor as an example, design of die structure and optimization of forging parameters are illustrated in detail here. The geometry parameters of the straight spur gear are shown in Table 1. During no-flash die forging of spur gear, 

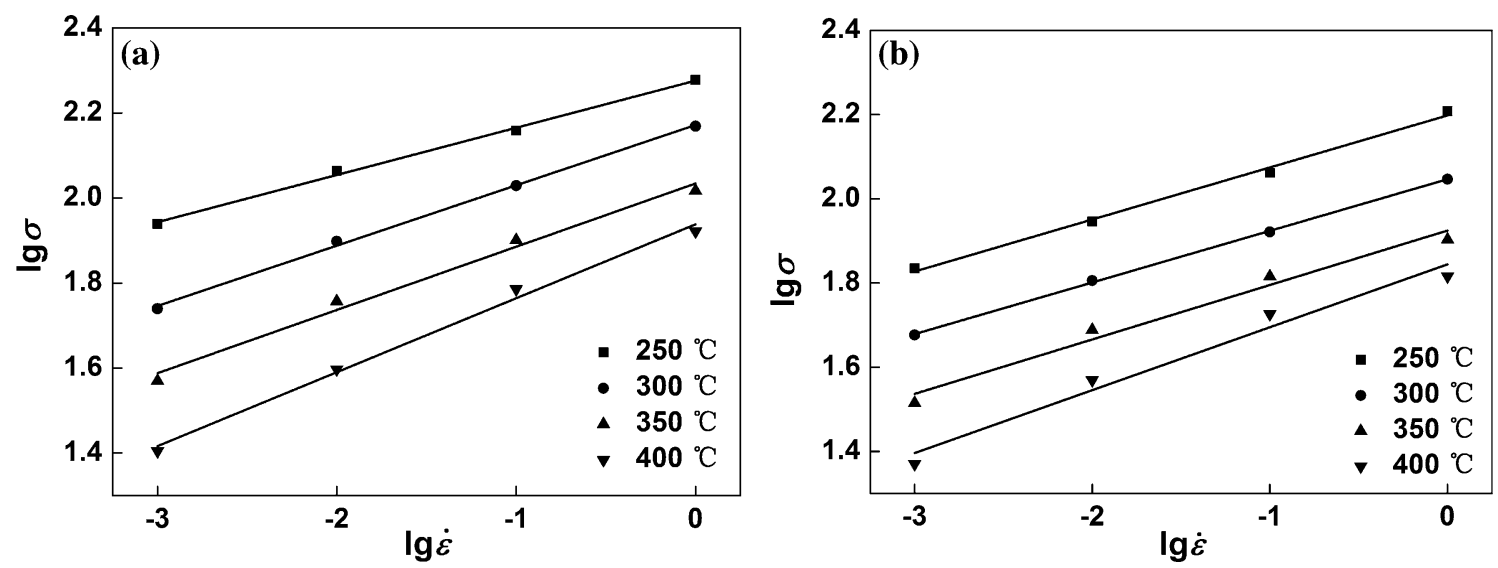

Fig. 2 Plot of $\lg \sigma$ versus $\lg \dot{\varepsilon}$ at strains of a $0.3, \mathbf{b} 0.7$
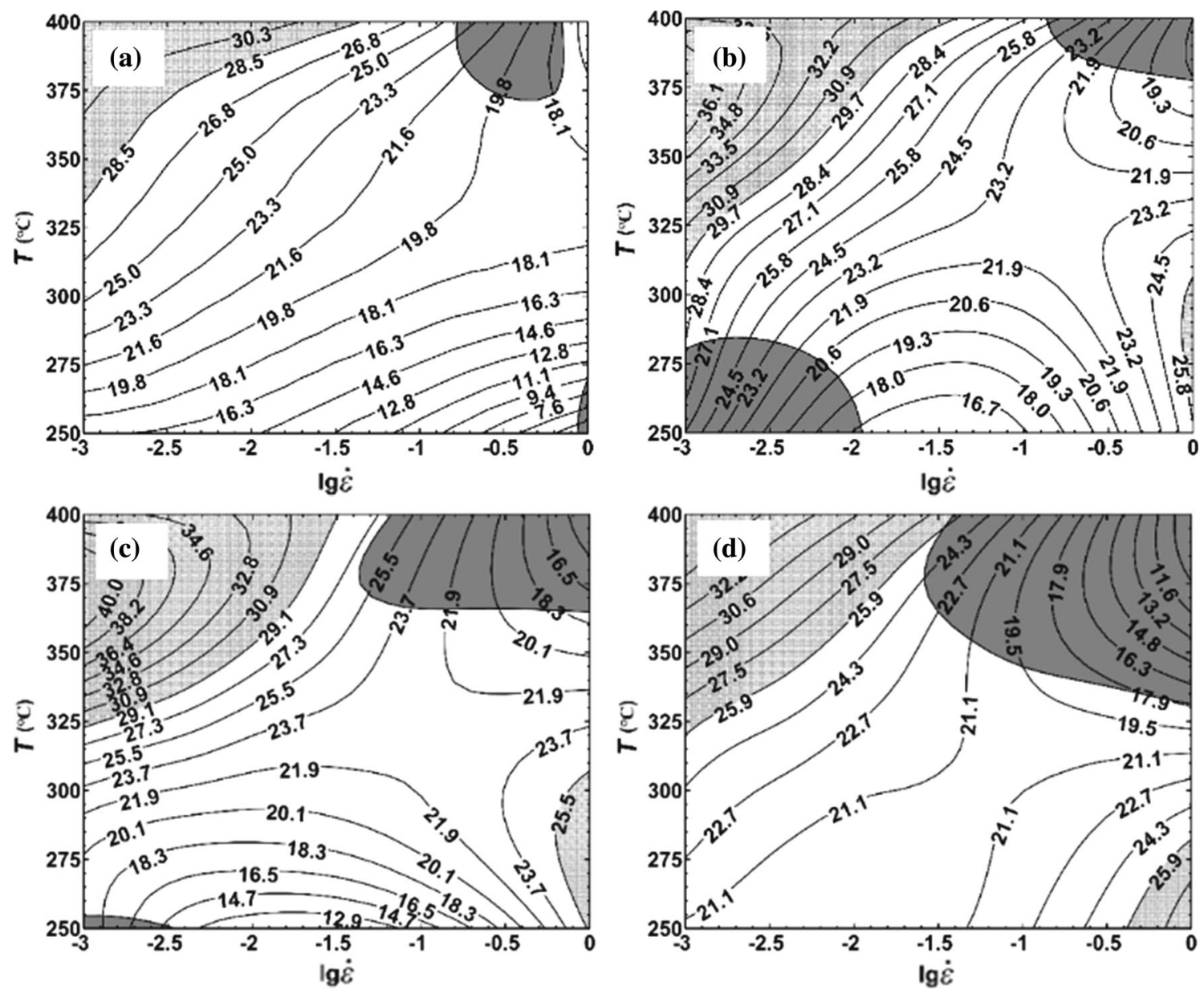

Fig. 3 Processing maps of AZ31B alloys at strains of a 0.2, b 0.4, c 0.6, d 0.8

the problems such as high forming load, difficulties in demolding and poor corner filling appear. To solve these problems, a die structure with linkage demolding device and divided flow mandrel is designed as shown in Fig. 4.

Before forging, upper and lower platens are fixed on upper and lower workbenches of the press, respectively.
During forging, toothed punch moves down and pushes the billet to fill the female die. After gear forming, the upper platen and the toothed punch move upwards, and then the bar linkages connected with upper platen and lower bolster, respectively, are straightened. Thus, the lower bolster pushes the spring and the toothed ejector upwards, which 
contributes to the gear demolding. In addition, mandrel divided flow method is used to reduce the forming load since this method, firstly proposed by Kondo et al. [28], significantly increases the non-contacting area between the billet and the die. The enlarged schematic diagram of this method is also given in Fig. 4.

\subsubsection{Finite Element Model for Gear Forging}

In this work, processing map of AZ31B alloys was integrated into the coupled thermal-mechanical FE model to simulate the distribution of deformation and flow instability during gear forging process. The commercially FEM software MSC Marc was applied due to its success in dealing with nonlinear problems, such as geometric, material and contact nonlinearity. In order to reduce computational time, one tooth was taken for FE analysis considering the symmetry of the investigated gear. The toothed punch, female die, mandrel and toothed ejector were set as rigid bodies, and the billet was set as elasticplastic body. The heat transfer coefficient between samples and environment, samples and dies are 20 and $3000 \mathrm{~W} /$ $\left(\mathrm{m}^{2}{ }^{\circ} \mathrm{C}\right)$, respectively. Heat generation conversion factor and friction coefficient are 0.9 and 0.3 , respectively. The true stress and strain data of AZ31B alloys were imported into the FE model through user-defined material library. The developed processing maps as described in Sect. 2.1 were integrated with the FE model through secondary development interface by FORTRAN language.

\section{Construction of Response Surface Model for Workability Domain}

\subsection{Workability Domain for Gear Forging}

The processing map of AZ31B alloys shown in Fig. 3 indicates that the onset of flow instability is sensitive to deformation parameters. In this work, workability domain was defined as the range of deformation parameters, where no flow instability occurs during gear forging.

Workability domain for gear forging is not completely consistent with the temperature-strain rate window given by Fig. 3. The reason lies in a fact that deformation is highly non-uniformly distributed in the forged gear due to its complicated geometry and the friction between the billet and dies, which has been illustrated in detail in our previous work [29]. Even if deformation parameters are chosen in the stability region, local instability may still be observed in the forged gear. In order to explain this phenomenon, deformation temperature of $320{ }^{\circ} \mathrm{C}$ and apparent average strain rate of $0.63 \mathrm{~s}^{-1}$ were applied to simulate the distribution of instability parameter in the forged gear. The apparent average strain rate $(\tilde{\tilde{\varepsilon}})$ is related to punch velocity $(V)$ as [30]:

$V=H 0 \tilde{\dot{\varepsilon}} \exp (-\tilde{\dot{\varepsilon}} t)$

where $H_{0}$ is the initial height of billet, and $t$ is the forging time. Figure 5a shows the simulated distribution of instability parameter in the forged gear. It is found that flow instability occurs mostly at the tooth part, especially at the tooth tip and tooth root (in blue region) although the chosen parameters locate in the region without the onset of flow instability. The most serious flow instability locates at tooth tip near the bottom of the flat end of the gear as marked with a circle in Fig. 5a. Figure $5 \mathrm{~b}$ presents the straight spur gear forged under the same condition. Poor filling is found at the tooth tip near the bottom of flat end of gear as predicted by the numerical simulation.

During hot forging, any local flow instability may cause poor forming quality. In FE simulation, values of effective strain, effective strain rate and temperature at each node are different. Thus calculated value of instability parameter at each node is also different. It can be inferred that there is no onset of flow instability in the gear if the minimal instability parameter is always greater than zero during the whole forging process. Figure 6 presents the variation of minimal instability parameter with reduction percent when the gear is forged at temperature of $320{ }^{\circ} \mathrm{C}$ and apparent average strain rate of $0.63 \mathrm{~s}^{-1}$. The reduction percent, $R_{\mathrm{P}}$, is defined as the ratio between current stroke and total stroke as the forging is complete. As shown in Fig. 6, flow instability will occur when $R_{\mathrm{P}}$ is smaller than $L_{1}$ or greater than $L_{2}$, while flow instability will not occur if the value of $R_{\mathrm{P}}$ is between $L_{1}$ and $L_{2}$ where the minimal instability parameter is greater than zero. $L_{1}$ and $L_{2}$ are defined as lower and upper critical value of reduction percent, respectively. Intervals of $\left[L_{1}, L_{2}\right]$ under different deformation parameters can be obtained by numerical simulations. Regime between the above intervals is defined as

Table 1 Geometric parameters of the straight spur gear

\begin{tabular}{llllll}
\hline Module & Teeth number & Pressure angle $\left({ }^{\circ}\right)$ & Reference diameter $(\mathrm{mm})$ & Addendum coefficient & Bore diameter $(\mathrm{mm})$ \\
\hline 0.5812 & 15 & 14.5 & 8.7173 & 1.0 & $3.985 \pm 0.01$ \\
\hline
\end{tabular}




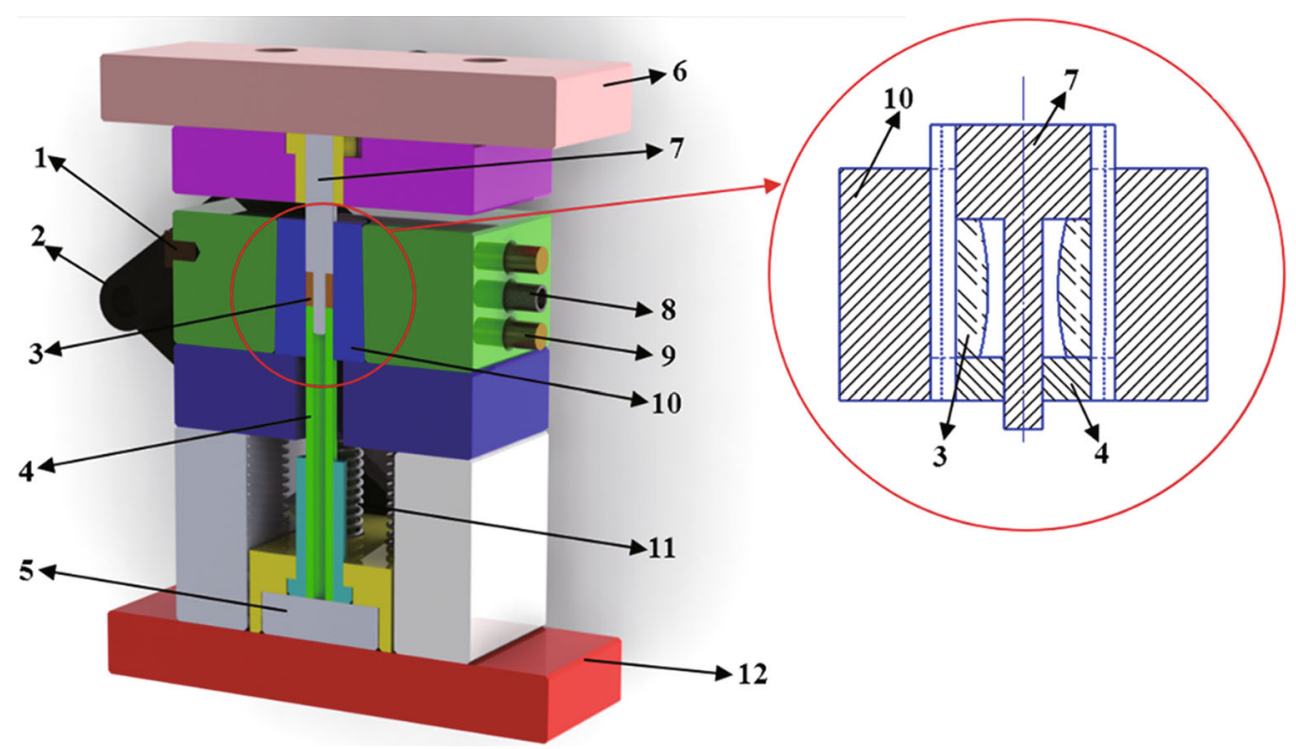

Fig. 4 Designed die structure with divided flow mandrel and linkage demolding device. 1-thermocouple, 2-linkage, 3-billet, 4-toothed ejector, 5-lower bolster, 6-upper platen, 7-toothed punch, 8-cooling pipe, 9-heating rod, 10-female die, 11-spring, 12-lower platen

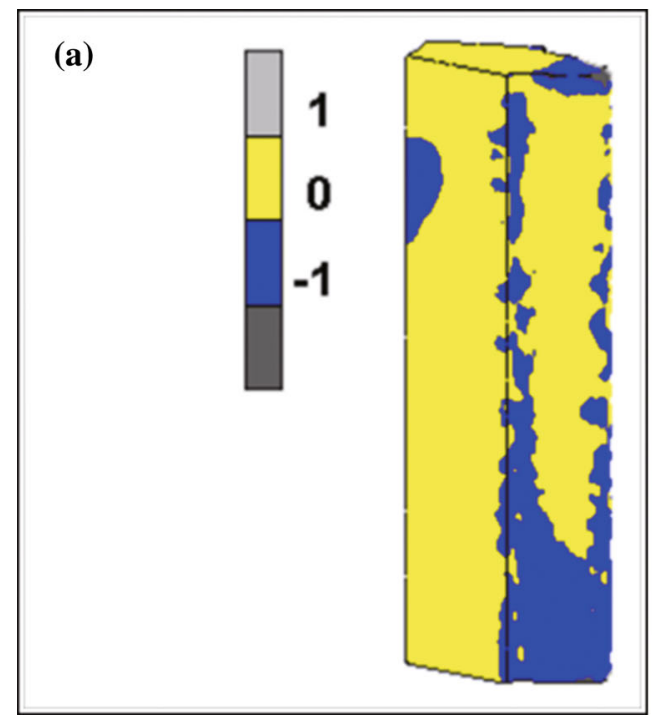

(b)

Fig. 5 Distribution of flow instability as forged at temperature of $320{ }^{\circ} \mathrm{C}$ and apparent average strain rate of 0.63 a simulated results, b experimental results

workability domain for gear forging where no flow instability occurs.

\subsection{Response Surface Model of Workability Domain}

Construction of response surface model for workability domain involves the following steps: (1) Determining the design variables influencing the onset of flow instability in gear forging and pre-defining their initial range; (2) generating sampling points in the range and obtaining the intervals of $\left[L_{1}, L_{2}\right]$ by numerical simulation at each sampling; and (3) using data obtained from all samplings to construct the response surface model of workability domain by least square regression method.

\subsubsection{Model Setup}

As illustrated above, initiation of flow instability during gear forging depends on deformation parameters, such as temperature, punch velocity and workpiece reduction. Deformation temperature $(T)$ and punch velocity $(V)$ were chosen as design variables, and lower and upper critical values of reduction percent $\left(L_{1}\right.$ and $\left.L_{2}\right)$ were set as response variables. Workability domain between $L_{1}$ and $L_{2}$ at given 


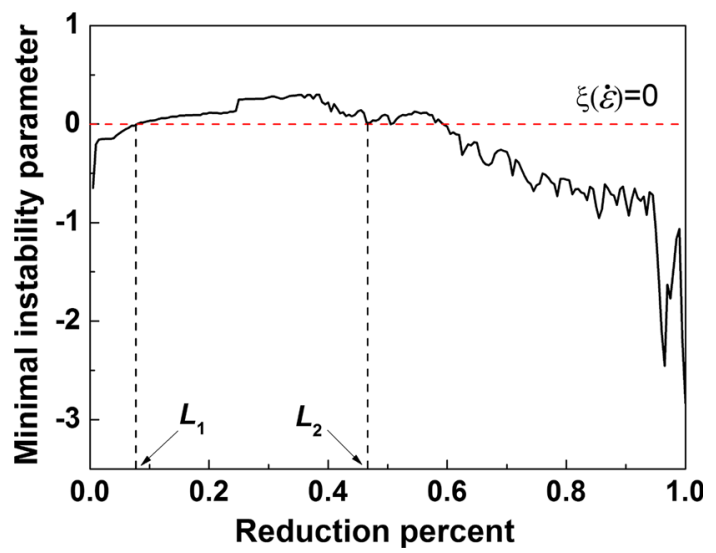

Fig. 6 Variation of minimal instability parameter with reduction percent at temperature of $320{ }^{\circ} \mathrm{C}$ and apparent average strain rate of $0.63 \mathrm{~s}^{-1}$

design space can be fitted by response surface model. The temperature range is from 250 to $400{ }^{\circ} \mathrm{C}$, and the punch velocity varies from 0.1 to $1 \mathrm{~mm} / \mathrm{s}$. Levels of design variables are given in Table 2. Design matrix including the actual, coded values of design variables, and the simulated values of response variables is listed in Table 3.

\subsubsection{Construction of Response Surface Model}

Constructing the surface of response variables involves several steps, such as model selection, model fitting and model checking. Firstly, an appropriate multi-order polynomial was chosen to approximate the real unknown relationship between design variables and response variables. Four kinds of approximation models, including the linear, 2F1 (quadratic model without square terms), quadratic and cubic polynomial, were built by least squares linear regression method. The goodness of fit was evaluated by several statistical terms, such as correlation coefficient $\left(R^{2}\right)$ and adjusted correlation coefficient $\left(R_{\text {adj }}^{2}\right)$.

Mathematically, $R^{2}$ is computed as the ratio of the regression sum of squares $\left(\mathrm{SS}_{\mathrm{reg}}\right)$ to the total sum of squares $\left(\mathrm{SS}_{\text {total }}\right)$. This number quantifies the percentage of response variable variance that can be explained by the regression equation. The value of $R^{2}$ is between 0 and 1 ;

Table 2 Design variables and their levels

\begin{tabular}{llllllll}
\hline Design variables & \multicolumn{1}{l}{ Levels } \\
\cline { 2 - 8 } & -1 & $-1 / 2$ & $-1 / 3$ & 0 & $1 / 3$ & $1 / 2$ & 1 \\
\hline$T\left({ }^{\circ} \mathrm{C}\right)$ & 250 & 287.5 & 300 & 325 & 350 & 362.5 & 400 \\
$V(\mathrm{~mm} / \mathrm{s})$ & 0.10 & 0.33 & 0.40 & 0.55 & 0.70 & 0.78 & 1.00 \\
\hline
\end{tabular}

the higher the value, the better the regression model captures the real unknown function.

$R^{2}=\frac{\mathrm{SS}_{\mathrm{reg}}}{\mathrm{SS}_{\text {total }}}=1-\frac{\mathrm{SS}_{\mathrm{res}}}{\mathrm{SS}_{\mathrm{total}}}=1-\frac{\sum_{i=1}^{n}\left(y_{i}-\hat{y}_{i}\right)^{2}}{\sum_{i=1}^{n}\left(y_{i}-\bar{y}\right)^{2}}$

where $\mathrm{SS}_{\mathrm{res}}$ is the residual sum of squares, $y_{i}$ is the observed response at the $i$ th sampling point, $\hat{y} i$ is the $i$ th predicted value, $\bar{y}$ is the average value of observations and $n$ is the number of sampling points.

The value of $R^{2}$ increases with increasing number of design variables. For the purpose of eliminating this effect, the $R_{\text {adj }}^{2}$ is applied by Wang and Lee [31] to correct the $R^{2}$ statistic.

Table 3 Design variables and two simulated responses

\begin{tabular}{|c|c|c|c|c|c|c|}
\hline \multirow[t]{2}{*}{ No } & \multicolumn{2}{|l|}{ Coded } & \multicolumn{2}{|l|}{ Actual } & \multicolumn{2}{|c|}{ Response variables } \\
\hline & $A$ & $B$ & $T\left({ }^{\circ} \mathrm{C}\right)$ & $V(\mathrm{~mm} / \mathrm{s})$ & $L_{1}$ & $L_{2}$ \\
\hline 1 & 0.500 & 0.500 & 362.50 & 0.78 & 0.000 & 0.610 \\
\hline 2 & 0.000 & 0.500 & 325.00 & 0.78 & 0.000 & 0.650 \\
\hline 3 & 1.000 & 1.000 & 400.00 & 1.00 & 0.000 & 0.505 \\
\hline 4 & -0.333 & 1.000 & 300.00 & 1.00 & 0.000 & 1.000 \\
\hline 5 & 1.000 & 0.000 & 400.00 & 0.55 & 0.000 & 0.615 \\
\hline 6 & 0.000 & 0.000 & 325.00 & 0.55 & 0.455 & 0.925 \\
\hline 7 & 0.000 & -0.500 & 325.00 & 0.33 & 0.390 & 0.970 \\
\hline 8 & -1.000 & -1.000 & 250.00 & 0.10 & 0.000 & 1.000 \\
\hline 9 & 1.000 & -1.000 & 400.00 & 0.10 & 0.000 & 0.955 \\
\hline 10 & -0.500 & 0.000 & 287.50 & 0.55 & 0.435 & 1.000 \\
\hline 11 & -0.333 & 0.333 & 300.00 & 0.70 & 0.460 & 1.000 \\
\hline 12 & -1.000 & 0.000 & 250.00 & 0.55 & 0.775 & 1.000 \\
\hline 13 & -0.333 & -1.000 & 300.00 & 0.10 & 0.000 & 1.000 \\
\hline 14 & 0.500 & 0.000 & 362.50 & 0.55 & 0.000 & 0.605 \\
\hline 15 & 1.000 & 0.333 & 400.00 & 0.70 & 0.000 & 0.600 \\
\hline 16 & -0.500 & -0.500 & 287.50 & 0.33 & 0.000 & 1.000 \\
\hline 17 & -0.333 & -0.333 & 300.00 & 0.40 & 0.475 & 1.000 \\
\hline 18 & -1.000 & 0.333 & 250.00 & 0.70 & 0.775 & 1.000 \\
\hline 19 & 0.000 & 1.000 & 325.00 & 1.00 & 0.435 & 0.740 \\
\hline 20 & -1.000 & -0.333 & 250.00 & 0.40 & 0.685 & 1.000 \\
\hline 21 & 0.333 & 0.333 & 350.00 & 0.70 & 0.000 & 0.605 \\
\hline 22 & 1.000 & -0.333 & 400.00 & 0.40 & 0.000 & 0.640 \\
\hline 23 & 0.333 & -1.000 & 350.00 & 0.10 & 0.000 & 0.960 \\
\hline 24 & -1.000 & 1.000 & 250.00 & 1.00 & 0.815 & 1.000 \\
\hline 25 & 0.333 & 1.000 & 350.00 & 1.00 & 0.000 & 0.600 \\
\hline 26 & -0.500 & 0.500 & 287.50 & 0.78 & 0.435 & 1.000 \\
\hline 27 & 0.333 & -0.333 & 350.00 & 0.40 & 0.000 & 0.635 \\
\hline 28 & 0.500 & -0.500 & 362.50 & 0.33 & 0.000 & 0.655 \\
\hline 29 & 0.000 & -1.000 & 325.00 & 0.10 & 0.000 & 1.000 \\
\hline
\end{tabular}




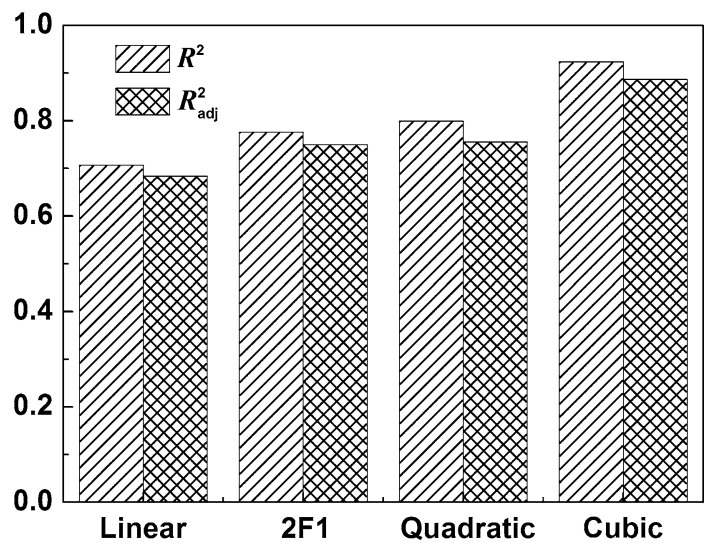

Fig. 7 Model summary statistics of $L_{2}$

$R_{\mathrm{adj}}^{2}=1-\left(\frac{n-1}{n-p}\right)\left(1-R^{2}\right)$

where $p$ is the number of regression coefficients.

Taking the response surface of $L_{2}$ as an example, these statistics for four different approximation models are compared in Fig. 7. It is shown that the cubic polynomial model is the most appropriate model due to its highest value of $R^{2}, R_{\text {adj }}^{2}$.

After selecting the order of polynomial equation, the linear regression method was applied to determine the regression coefficients and the analysis of variance (ANOVA) was performed to evaluate the significance of the regression model and that of individual model term. The insignificant terms were eliminated by step-wise regression method, and the reduced cubic polynomial response surface was obtained. Summary of results for $L_{2}$ is tabulated in Table 4. The Model $F$ value of 35.31 and $P$ value of less than 0.0001 imply that there is only a less than $0.01 \%$ chance that a model with such a large $F$ value could occur due to noise, and that the model is significant

Table 4 ANOVA for reduced cubic response surface of $L_{2}$

\begin{tabular}{llrlrr}
\hline Source & Sum of squares & $d f$ & $\begin{array}{l}\text { Mean } \\
\text { square }\end{array}$ & $F$ value & $\begin{array}{l}P \text { value } \\
\text { Prob. }>F\end{array}$ \\
\hline Model & 0.91 & 7 & 0.13 & 35.31 & $<0.0001$ \\
$A$ & 0.34 & 1 & 0.34 & 92.48 & $<0.0001$ \\
$B$ & 0.13 & 1 & 0.13 & 35.66 & $<0.0001$ \\
$A B$ & 0.069 & 1 & 0.069 & 18.70 & 0.0003 \\
$A^{2}$ & 0.001042 & 1 & 0.001042 & 0.28 & 0.6004 \\
$B^{2}$ & 0.021 & 1 & 0.021 & 5.76 & 0.0258 \\
$A B^{2}$ & 0.012 & 1 & 0.012 & 3.19 & 0.0885 \\
$A^{3}$ & 0.10 & 1 & 0.10 & 27.43 & $<0.0001$ \\
Residual & 0.077 & 21 & 0.003684 & & \\
Cor total & 0.99 & 28 & & & \\
\hline
\end{tabular}

[32]. Values of "Prob. $>F$ " indicate that whether or not the model terms are statistically significant. The smaller the $P$ value, the more significant the model term is [33]. So the significance of individual model term is ranked as $A>B>A^{3}>A B>B^{2}$, and deformation temperature is the most significant factor affecting the upper critical value of flow instability.

The reduced cubic polynomial response surface of $L_{2}$ can be expressed in terms of actual variables as

$$
\begin{aligned}
L_{2}= & -21.45097+0.21313 T+2.19317 V-8.52192 \\
& \times 10^{-3} T \times V-6.63071 \times 10^{-4} T^{2}-1.19296 V^{2} \\
& +4.64299 \times 10^{-3} T \times V^{2}+6.77486 \times 10^{-7} T^{3} .
\end{aligned}
$$

Figure 8 shows the 3D response surface of $L_{2}$ and its 2D contour plots. The designer can roughly predict that the flow instability will be observed in the forged gear if reduction percent is larger than the response predicted by the 3D surface. Therefore, the area with the predicted value of $L_{2}$ equal to or larger than 1 should be chosen to avoid the onset of flow instability in the later stage of deformation.

Similarly, the response surface model of $L_{1}$ was also obtained. The cubic polynomial model was chosen by comparing the goodness of fit for four different models. Table 5 shows the summary of ANOVA for the model and the individual model term of $L_{1}$. It can be seen that the regressed cubic polynomial for $L_{1}$ is significant and the significance of individual model term can be sorted as $A>A B>B^{2}>A B^{2}>A^{2}$. The deformation temperature is still the most significant factor in the controlling of flow instability. The reduced cubic polynomial response surface of $L_{1}$ can be expressed in terms of actual variables as

$$
\begin{aligned}
L_{1}= & -1.50702+6.7185 \times 10^{-3} T+14.15692 V \\
& -0.059522 T \times V-7.18716 \times 10^{-6} T^{2} \\
& -5.53374 V^{2}+5.8778 \times 10^{-5} T^{2} \times V \\
& +0.014435 T \times V^{2} .
\end{aligned}
$$

Figure 9 presents the 3D and 2D contour plots of response surface model for $L_{1}$. The flow instability will be observed in the forged gear if reduction percent is less than the response predicted by the 3D surface. So smaller value of $L_{1}$ is desirable to avoid flow instability in the initial stage of deformation.

\section{Model Analysis and Experiments Verification}

\subsection{Model Analysis}

Figure 10 shows the regressed response surfaces for $L_{1}$ and $L_{2}$ on the design space. Workability domain locates 


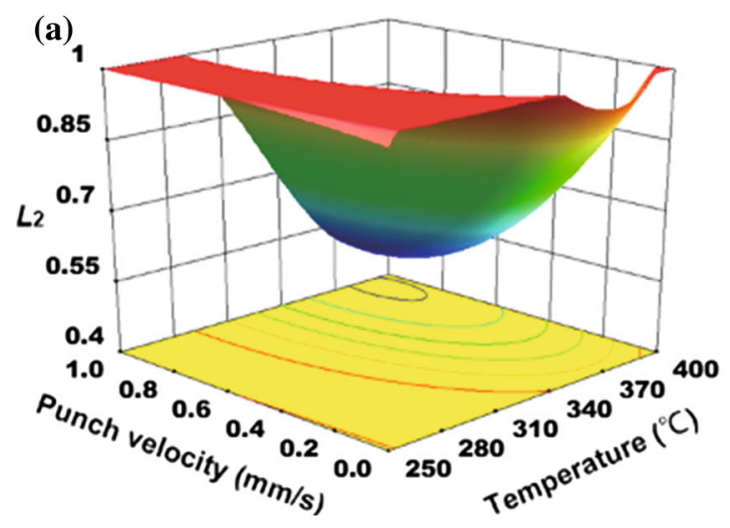

Fig. 8 Response surface model of $L_{2}$ a 3D plot, b 2D contour plot

Table 5 ANOVA for reduced cubic response surface of $L_{1}$

\begin{tabular}{llrlrr}
\hline Source & Sum of squares & $d f$ & $\begin{array}{l}\text { Mean } \\
\text { square }\end{array}$ & $F$ value & $\begin{array}{l}P \text { value } \\
\text { Prob. }>F\end{array}$ \\
\hline Model & 1.90 & 7 & 0.27 & 11.42 & $<0.0001$ \\
$A$ & 1.03 & 1 & 1.03 & 43.26 & $<0.0001$ \\
$B$ & 0.012 & 1 & 0.012 & 0.49 & 0.4913 \\
$A B$ & 0.17 & 1 & 0.17 & 7.34 & 0.0131 \\
$A^{2}$ & 0.10 & 1 & 0.10 & 4.35 & 0.0493 \\
$B^{2}$ & 0.15 & 1 & 0.15 & 6.33 & 0.0200 \\
$A^{2} B$ & 0.053 & 1 & 0.053 & 2.22 & 0.1509 \\
$A B^{2}$ & 0.11 & 1 & 0.11 & 4.83 & 0.0394 \\
Residual & 0.50 & 21 & 0.024 & & \\
Cor total & 2.40 & 28 & & &
\end{tabular}

between the surfaces of $L_{1}$ and $L_{2}$. In Fig. 10, the value of $L_{2}$ was taken as 1 if its calculated value from RSM is larger than 1 and the value of $L_{1}$ was set as 0 if its calculated value is less than 0 so that the predictions from RSM have obvious physical meaning in accordance with the actual forging process. In general, domain with low temperature and low punch velocity is desirable for successful forging of AZ31B straight spur gear, because the workability domain covering the interval from 0 to 1 indicates no flow instability occurs during the whole forging process.

\subsubsection{Effects of Deformation Temperature on Flow Instability}

According to the ANOVA shown in Tables 4 and 5, it is concluded that hot workability for AZ31B straight spur gear forging is mostly sensitive to deformation temperature. Figure 11 exhibits the effects of deformation temperature on responses of $L_{1}$. For a specific punch velocity

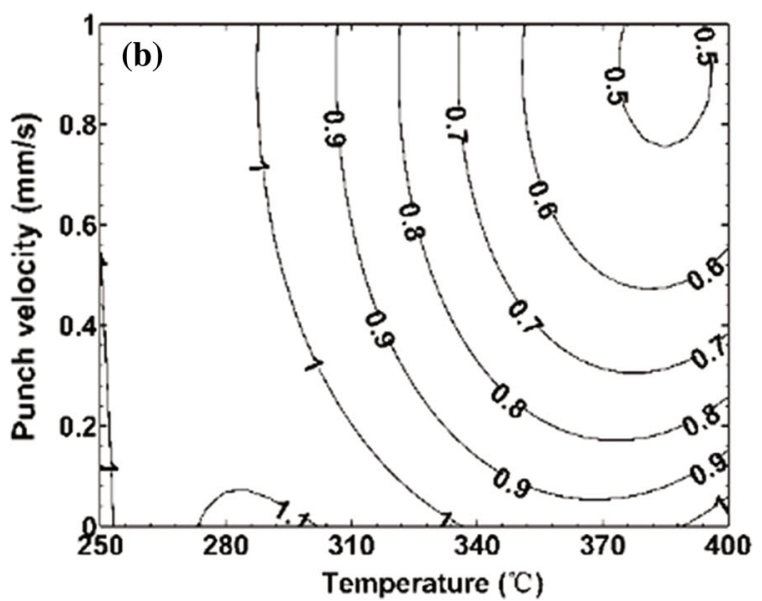

of $V>0.1 \mathrm{~mm} / \mathrm{s}, L_{1}$ decreases with increasing deformation temperature. This means that flow instability is prone to take place at lower temperatures, such as 250 and $300{ }^{\circ} \mathrm{C}$, and it will not occur if deformation temperature is higher than $350^{\circ} \mathrm{C}$ in the early stage of forging. The reason lies in the fact that not only basal slip and twinning but also nonbasal slip and grain boundary sliding will initiate as deformation temperature exceeds $350{ }^{\circ} \mathrm{C}$. Therefore, the increase in plastic deformation capability of magnesium alloys at higher temperatures reduces the possibility of the occurence of flow instability at the beginning of forging.

As shown in Fig. 11, values of $L_{2}$ decrease with increasing deformation temperature as $V>0.4 \mathrm{~mm} / \mathrm{s}$ and it is close to 1 at temperatures of 250 and $300{ }^{\circ} \mathrm{C}$ if $V \leq 0.4 \mathrm{~mm} / \mathrm{s}$. This indicates that flow instability is easier to occur at higher temperatures, such as 350 and $400{ }^{\circ} \mathrm{C}$ in the later stage of forging, i.e., the later tooth filling stage. This is because DRX-ed grain size increases with increasing temperature. On the one hand, non-basal slip is only activated near grain boundaries if grain size is larger than $10 \mu \mathrm{m}$, which reduces the plastic deformation capability of magnesium alloys as compared with fine-grained materials; on the other hand, grain boundary sliding contributes more to total strain as deformation increases. Intercrystalline cracking or wedge cracking will emerge if stress concentration at triple junctions of grain boundaries cannot be relaxed. This is especially true for coarse-grained materials.

\subsubsection{Effect of Punch Velocity on Flow Instability}

Figure 11 also presents the effects of punch velocity on response of $L_{1}$ and $L_{2}$. It can be seen that the effect of temperature on response variables becomes more significant as the punch velocity increases. The safe interval of $\left[L_{1}, L_{2}\right]$ reduces with increasing punch velocity for a 


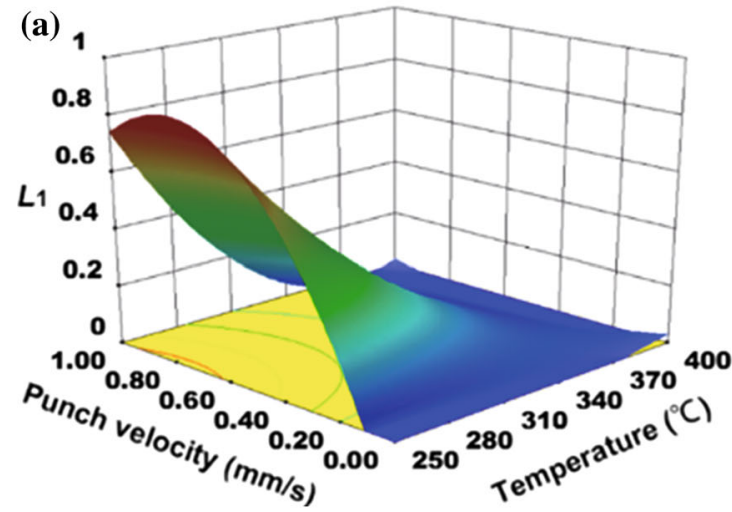

Fig. 9 Response surface model of $L_{1}$ a 3D plot, b 2D contour plot

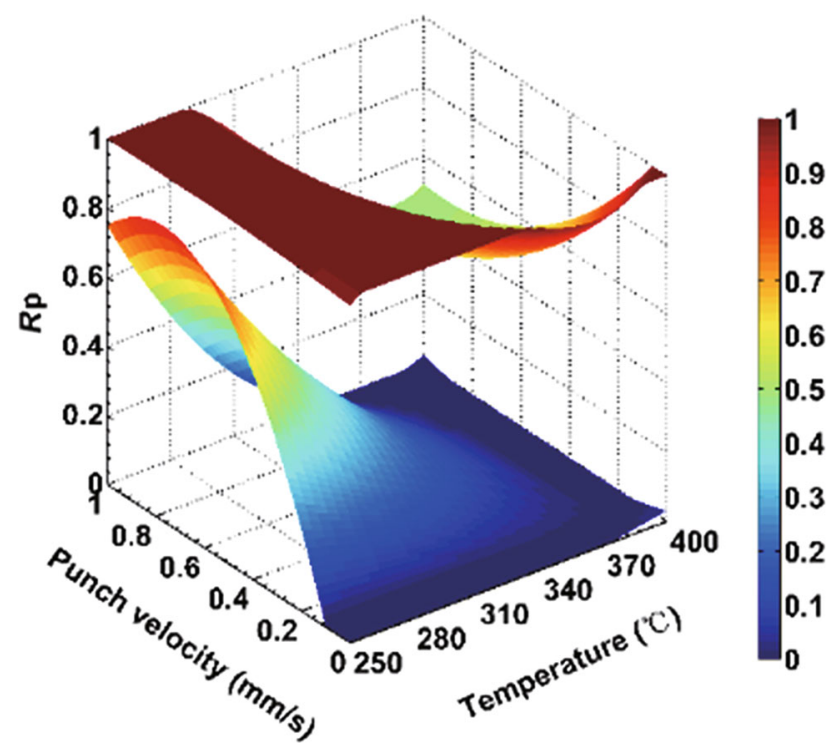

Fig. 10 Workability domain for AZ31B straight spur gear forging

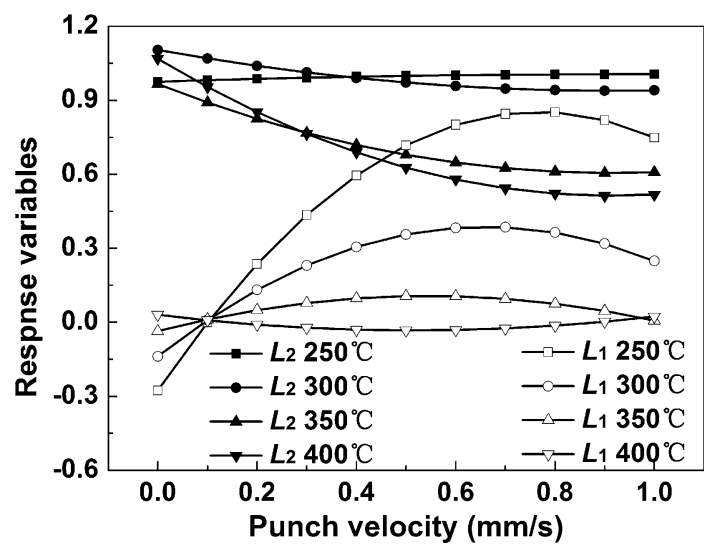

Fig. 11 Effects of deformation temperature and punch velocity on responses of $L_{1}$ and $L_{2}$

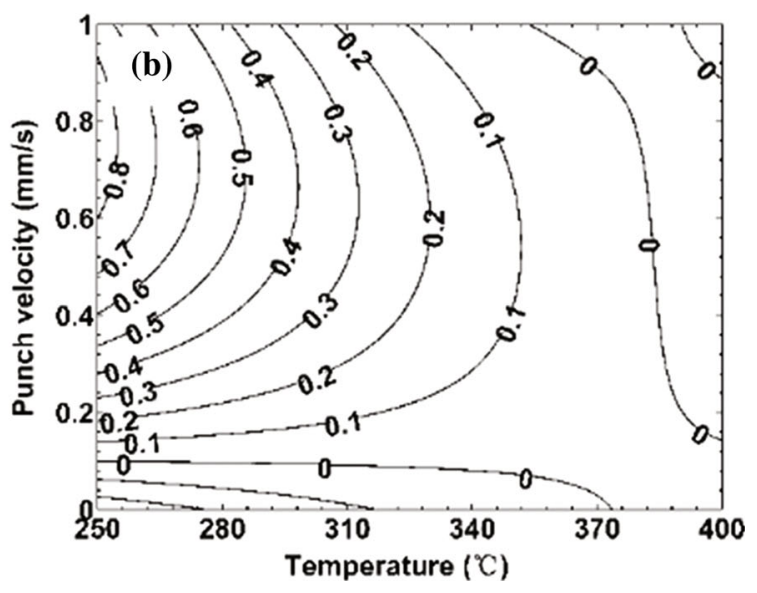

specific forging temperature. At lower temperatures of 250 and $300{ }^{\circ} \mathrm{C}$, the increase in punch velocity enlarges the value of $L_{1}$, i.e., the critical value for the onset of flow instability in the early stage of forging; while at higher temperatures of 350 and $400{ }^{\circ} \mathrm{C}$, the increase in punch velocity reduces the critical value for the onset of flow instability in the later stage of forging. In addition, when $V \leq 0.1 \mathrm{~mm} / \mathrm{s}$, no flow instability is observed in the temperature range from about 250 to $300{ }^{\circ} \mathrm{C}$.

For the case of low temperature and high punch velocity, the weak role of dynamic recovery (DRV) and DRX at the initial stage of deformation leads to multiplication and tangle of dislocations. If the resulting stress concentration at grain boundaries or in the interior of grains cannot be relaxed rapidly, cracking appears and results in the onset of flow instability in the early stage of forging. The role of DRX increases with the development of deformation. The fine DRX-ed grains formed at low temperature promote grain boundary sliding and thus improve the plastic formability of materials. So flow instability will not occur in the later stage of forging, while for the case of high temperature and high punch velocity, the activation of basal slip and non-basal slip at the initial stage of forging effectively improves the plastic formability of magnesium alloys as illustrated in Sect. 4.1.2. But the coarse DRX-ed grain formed at high temperature is difficult to deform compatibly when the punch velocity is high. As a result, cracking initiates at the later stage of deformation.

\subsection{Experiments Verification}

Experiments of straight spur gear forging were conducted to verify the reliability of the workability domain developed by response surface model and the numerical simulation. Figure 12 gives the 2D cross-sectional views of 3D workability domain at the punch velocity of 0.1 and $1 \mathrm{~mm} /$ $\mathrm{s}$. At the punch velocity of $0.1 \mathrm{~mm} / \mathrm{s}$, the temperature range 

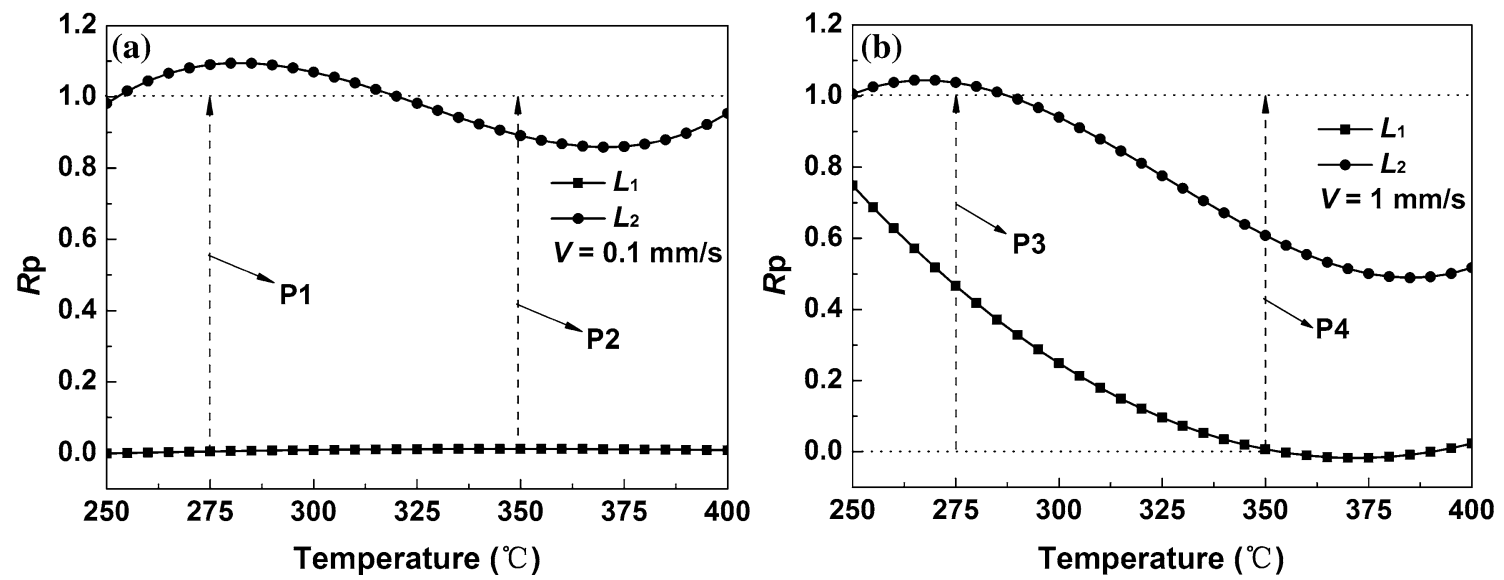

Fig. $122 \mathrm{D}$ cross section of $3 \mathrm{D}$ workability domain at punch velocity of a $0.1 \mathrm{~mm} / \mathrm{s}, \mathbf{b} 1 \mathrm{~mm} / \mathrm{s}$

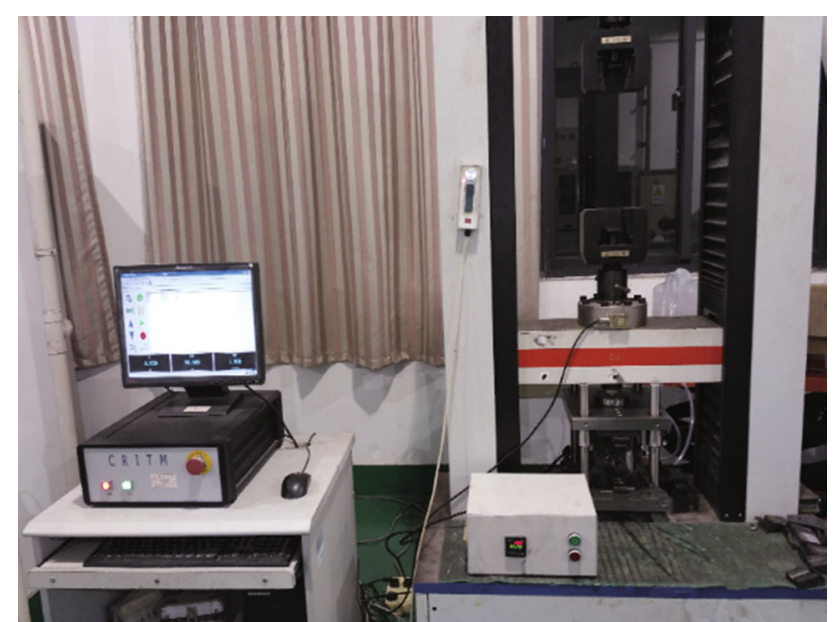

Fig. 13 Photograph of forging equipments

of $255-320{ }^{\circ} \mathrm{C}$ is the safe interval for spur gear forging, where no flow instability occurs. If the temperature is higher than $320^{\circ} \mathrm{C}$, flow instability will occur in the later stage of tooth filling as shown in Fig. 12a. At the punch velocity of $1 \mathrm{~mm} / \mathrm{s}$, flow instability is unavoidable in the temperature range of $250-400{ }^{\circ} \mathrm{C}$. It will occur at the initial stage of gear forging if $T \leq 280{ }^{\circ} \mathrm{C}$; at the later stage if $T \geq 350{ }^{\circ} \mathrm{C}$, and at both the initial and later stage if $280{ }^{\circ} \mathrm{C}<T<350{ }^{\circ} \mathrm{C}$. Four different processing paths were chosen as shown in Fig. 12: (1) P1 at $T=275^{\circ} \mathrm{C}$ and $V=0.1 \mathrm{~mm} / \mathrm{s}$, locating within the workability domain; (2) P2 at $T=350{ }^{\circ} \mathrm{C}$ and $V=0.1 \mathrm{~mm} / \mathrm{s}$; (3) P3 at $T=275{ }^{\circ} \mathrm{C}$ and $V=1 \mathrm{~mm} / \mathrm{s}$; and (4) $\mathrm{P} 4$ at $T=350{ }^{\circ} \mathrm{C}$ and $V=1 \mathrm{~mm} / \mathrm{s}$. The later three processing paths locate beyond the workability domain.

\subsubsection{Experimental Procedure and Equipment}

As shown in Fig. 13, forging experiments were carried out on a $100 \mathrm{kN}$ electro-hydraulic servo testing machine. Heating rods and thermocouples were connected with the designed die structure to achieve the isothermal forging. As described in Sect. 3.2, deformation temperature is the most significant factor influencing flow instability. Thus accurate and reliable temperature control device is necessary for forging spur gear of AZ31B alloys. The mixture of $\mathrm{MoS}_{2}$ and grease was used as lubricant to decrease the friction between billet and die.

\subsubsection{Results and discussion}

After cleaning and deburring, the forged gears obtained by P1, P2, P3 and P4 processing paths were presented in Fig. 14. The straight spur gear forged by P1 path was fully filled along the height of the tooth as shown in Fig. 14a. In Fig. 14b, the straight spur gear forged by P2 path was filled rather well but cracking and peeling were observed locally at the tooth tip and at the bottom of the tooth. This may be associated with the onset of flow instability at the later stage of tooth filing. The teeth of the gear obtained by P3 path were basically broken at about a quarter of tooth height as shown in Fig. 14c. This may be due to the onset of flow instability at the beginning stage of forging, leading to the peeling off of most part of the tooth. The teeth of the gear forged by $\mathrm{P} 4$ path were basically broken at about a half of tooth height, and rough surfaces were observed along the axial direction of the tooth. The reason may be associated with severe flow instability at the later stage of forging as predicted by workability domain given in Figs. 10 and 12. 


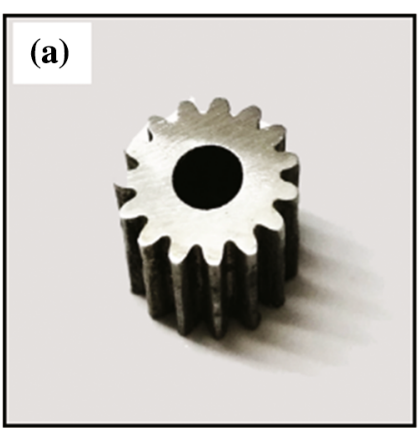

(b)

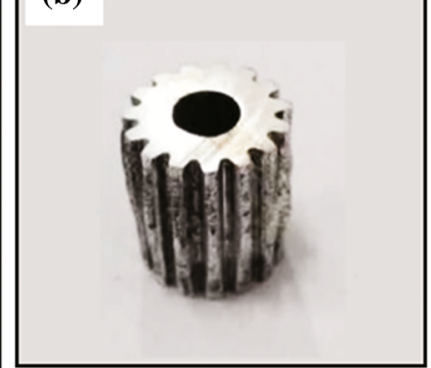

(c)

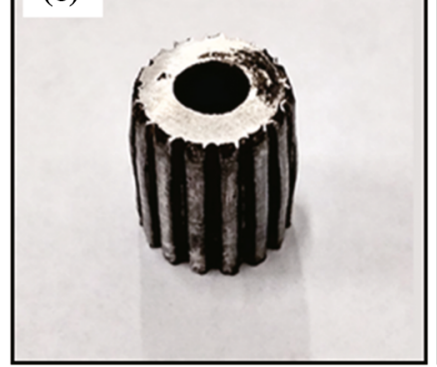

(d)

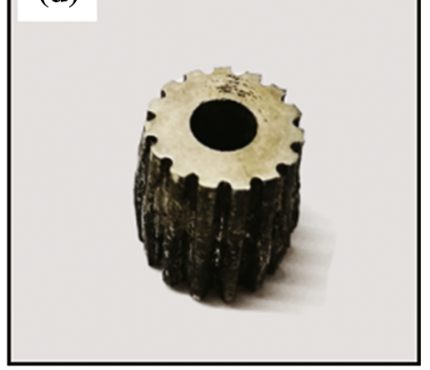

Fig. 14 Photographs of the straight spur gear forged by four different processing paths as a P1, b P2, c P3, d P4

Metallographic observation was carried out on the cross section of the forged gear. Schematic diagram for the observation sites is given in Fig. 15. Figure 16 shows the metallographic microstructures of the gear forged by P1 path (the P1 gear) at the positions of tooth tip (S1), tooth root (S2) and the position near the inner hole (S3). Finegrained equiaxial microstructure is typically observed at the positions of S1 (Fig. 16a) and S2 (Fig. 16b). Only a small amount of large grains are observed in these areas. This is because fairly large deformation level and deformation velocity at these regions lead to adequate development of DRX. At the site of S3, grain size is rather nonuniformly distributed as shown in Fig. 16c. The reason lies in the fact that the deformation level is rather small in this area due to the friction between the billet and the die, resulting in incomplete development of DRX. According to the processing map of AZ31B alloys, the peak efficiency of power dissipation at the lower temperature region increases with the strain when the strain is larger than 0.5 . The value of $\eta$ is larger than $25 \%$, which indicates that dynamic recrystallization plays an important role in microstructural evolution. The metallographic characteristics are consistent with the prediction from the processing map and the observations described by Lv et al. [34].

In magnesium alloys, the dominant deformation mechanism depends on deformation temperature and microstructure characteristics, such as grain size and initial texture. Good filling of the P1 gear lies in the fact that prismatic slip operates extensively, and a small amount of pyramidal slip initiates when the temperature is higher than $225^{\circ} \mathrm{C}$. Together with the basal slip, these operating slip systems enhance the ductility of magnesium alloys [35]. However, the great difference in the critical resolved shear stress between the basal slip and non-basal slip can still produce obvious stress concentration at grain boundaries of polycrystalline magnesium alloys, although the activation of non-basal slip can relax the stress concentration and facilitate the homogeneous deformation capacity [36]. Here the stress concentration is mainly released through grain boundary slip because fine and uniform recrystallized grain

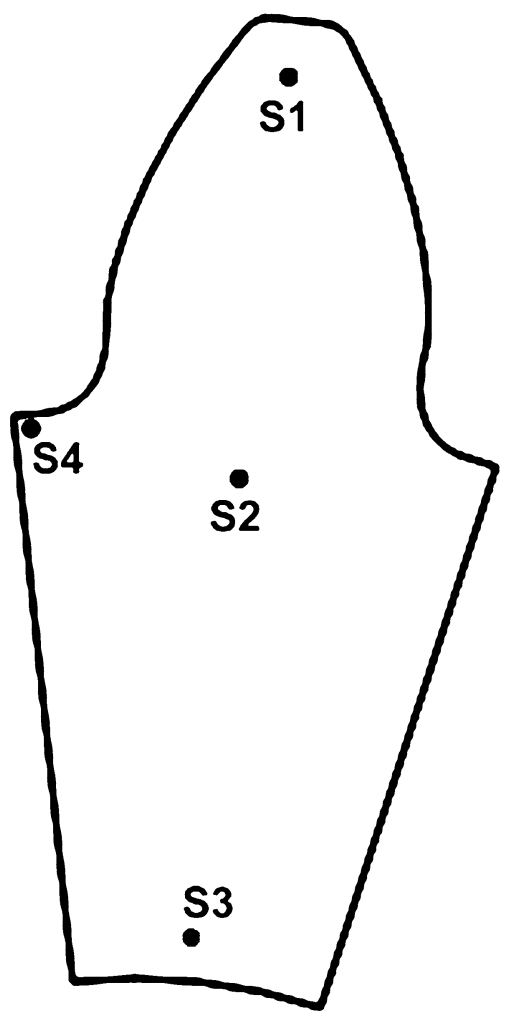

Fig. 15 Schematic diagram of observation sites

is beneficial to grain boundary slip but suppresses the formation of twins. Meanwhile, the initiation of grain boundary slip further improves the formability of magnesium alloys [37].

Figure 17 presents the metallographic microstructures at the tooth root and close to the inner hole since poor tooth tip filling is observed in the gears forged by P2, P3 and P4 paths. As shown in Fig. 17a, c, coarse grain with wavy grain boundary, typically recrystallized grain, is observed in the gear obtained by $\mathrm{P} 2$ path at the sites of $\mathrm{S} 3$ and the tooth root between two neighboring teeth (S4). Meanwhile, twinning and intercrystalline cracking are observed at the S2 in Fig. 17b. These microstructure characteristics are associated with the deformation mechanisms of AZ31B 

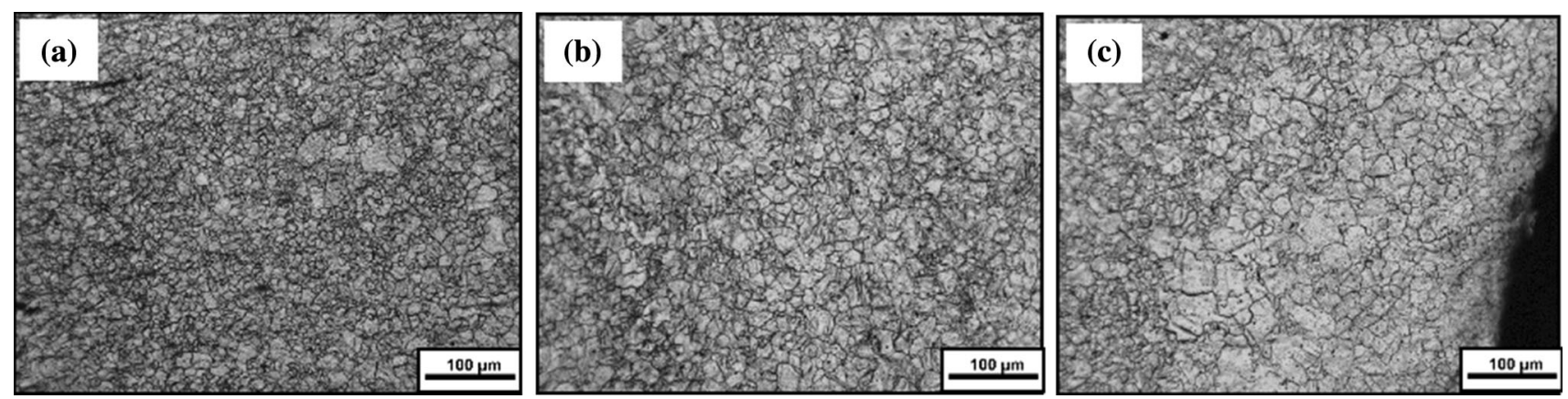

Fig. 16 Metallographic microstructure of the straight spur gear forged by P1 path at the positions of a S1, b S2, c S3
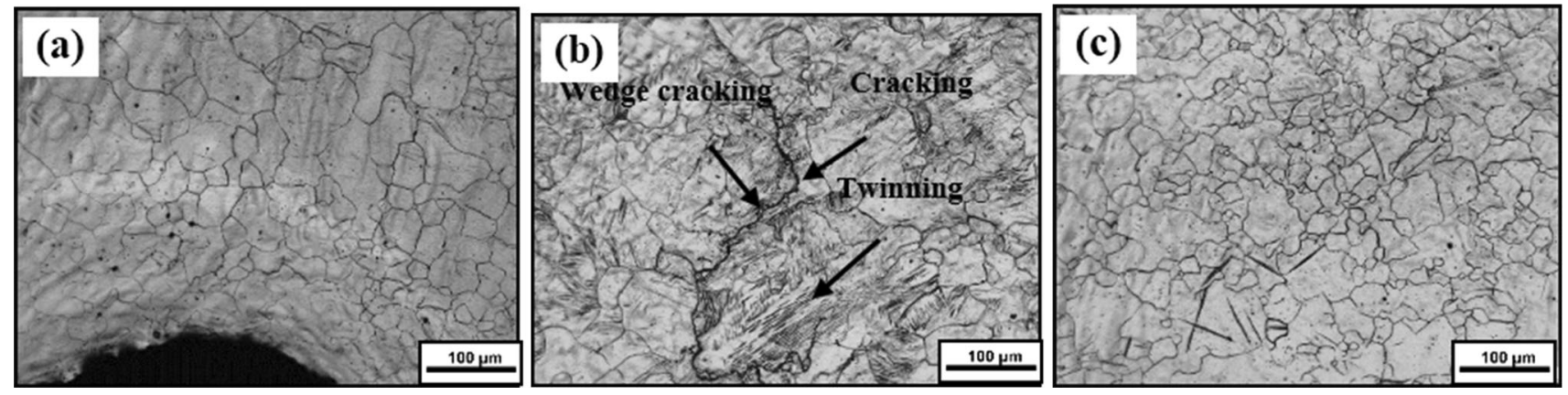

Fig. 17 Metallographic microstructure of the straight spur gear forged by P2 path at the sites of a S4, b S2, c S3
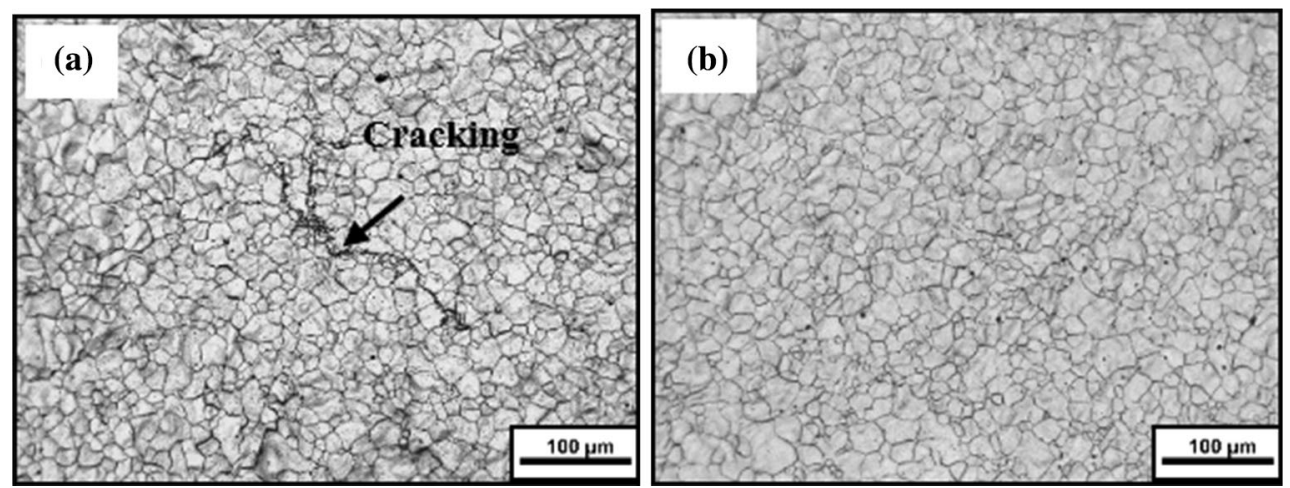

Fig. 18 Metallographic microstructure of the straight spur gear forged by P3 path at the sites of a S2, b S3

alloys. The extensive operation of the first-order and the second-order pyramidal slip systems for the P2 gear deformed at $350{ }^{\circ} \mathrm{C}$ promotes cross-slip and nucleation of DRX $[38,39]$. Therefore, DRX is controlled by the rate of grain boundary migration, which is high at temperature of $350{ }^{\circ} \mathrm{C}$ and results in coarse DRX grains. For coarsegrained materials undergoing hot deformation, stress concentration relaxed by grain boundary slip is limited, whereas that relaxed by twinning plays an important role. However, only a small amount of strain can be accommodated by twinning, since it merely allows simple to shear along one direction, which promotes the onset of cracking and flow instability [40].

Figure 18 shows the microstructures of the gears obtained by the P3 path. A large number of fine grain distributed around the cracks is observed at the S2 in Fig. 18. This is a typical characteristic of flow localization [41]. The deformation temperature of the P3 gear is the same as that of the P1 gear, but the punch velocity increases to $1 \mathrm{~mm} / \mathrm{s}$. The efficiency of power dissipation is about $20 \%$, that is, DRX cannot develop completely in the P3 gear. This is supported by a typically incomplete DRX 

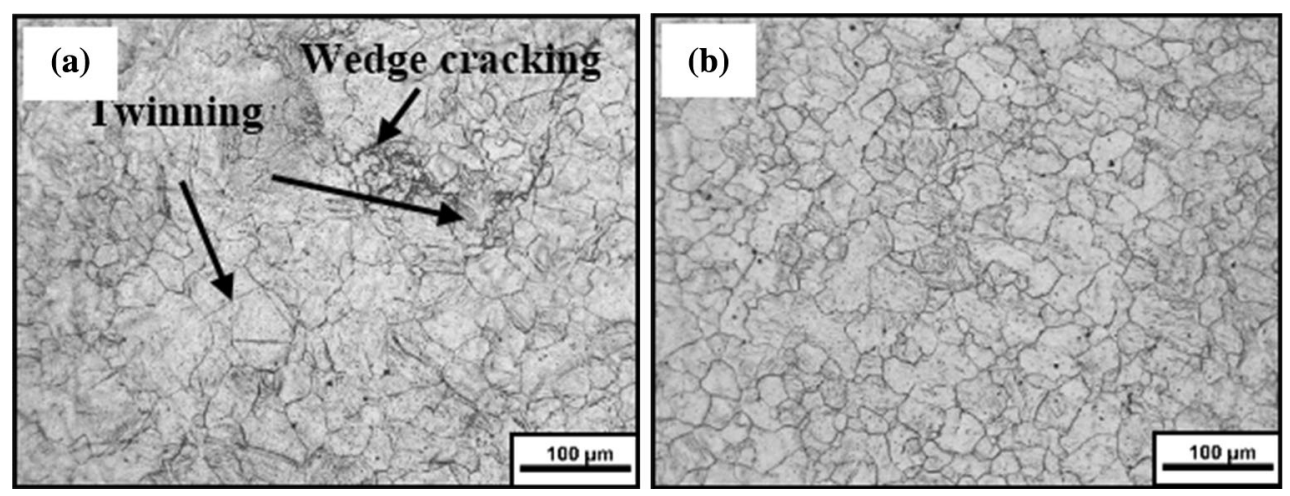

Fig. 19 Metallographic microstructure of the straight spur gear forged by P4 path at the sites of a S2, b S3

microstructure observed at the site of S3 where fine recrystallized grains are found around the coarse initial grain of about $40 \mu \mathrm{m}$ (Fig. 18b). The dominant deformation mechanism under $\mathrm{P} 3$ path is similar to that of $\mathrm{P} 1$ path. However, incomplete DRX and refined DRX grains provide potential path for localization flow that leads to local temperature rising, deterioration of local flow and generation of cracking as shown in Fig. 18a.

Figure 19 gives the microstructures of the gears forged by the P4 path. Compared with those obtained by the P2 path, finer grain and a smaller amount of twinning are observed. Wedge cracking is also found at the tooth root near the middle part of the tooth. The deformation mechanism and the reason of flow instability are similar to that of P2 path. Based on the above experimental analysis, it can be concluded that tooth filling effect of the gear forged by P1 path is the best one among four different processing paths. Meanwhile, fine-grained and rather uniformly distributed microstructure is achieved, especially at the tooth part of the gear, while different level of damage is observed at the tooth part in the gear obtained by the other three paths. The forging experiments demonstrate the availability of the workability domain developed by combining the numerical simulation and RSM. This proposed technology can also be applicable for other complex-shaped forgings.

\section{Conclusions}

1. The response surface model of the workability domain for AZ31B straight spur gear forging can be determined by FE simulation integrated with processing map. The variance analysis of the response surface shows that deformation temperature is the most significant variable influencing the hot workability of the forged AZ31B spur gear. Meanwhile, the workability domain decreases with the increase in punch velocity.

2. Forging experiments using the processing path within the workability domain can produce the gear of good tooth filling and fine-grained microstructure, while poor tooth filling, flow localization and cracking are observed in the gears forged by the processing path extending outside of the workability domain. This demonstrates the availability of the method developed in this work.

3. Different deformation mechanisms, such as grain boundary slide, dislocation slide and twinning, as well as microstructure characteristics under different forging parameters are responsible for the variation of workability domain of AZ31B straight spur gear forged at the design space.

Acknowledgements The authors gratefully acknowledge the funding support from the National Natural Science Foundation of China (No. 51675335), the Jiangsu Industry University Research Cooperation Prospective Joint Research Project (No. BY2016069-07), and the Yangzhou Industry University Research Cooperation Project (No. YZ 2016241). The authors also gratefully acknowledge the helpful comments and suggestions made by Juan Liu at the Shanghai Jiao Tong University. Many thanks are also given to Jing Bai at Southeast University for his help in material preparation.

\section{References}

[1] Y.V.R.K. Prasad, H.L. Gegel, S.M. Doraivelu, J.C. Malas, J.T. Morgan, K.A. Lark, D.R. Barker, Metall. Mater. Trans. A 15, 1883 (1984)

[2] K.K. Deng, J.C. Li, F.J. Xu, K.B. Nie, W. Liang, Mater. Des. 67, $72(2015)$

[3] M.L. Wang, P.P. Jin, J.H. Wang, L. Han, C. Cui, Acta Metall. Sin. (Engl. Lett.) 27, 63 (2014)

[4] M. Shalbafi, R. Roumina, R. Mahmudi, J. Alloys Compd. 696, 1269 (2017)

[5] M. Sarebanzadeh, R. Mahmudi, R. Roumina, Mater. Sci. Eng. A 637, 155 (2015)

[6] Y.Y. Dong, C.S. Zhang, G.Q. Zhao, Y.J. Guan, A.J. Gao, W.C. Sun, Mater. Des. 92, 983 (2016)

[7] P. Zhou, Q.X. Ma, Acta Metall. Sin. (Engl. Lett.) 30, 907 (2017)

[8] E.X. Pu, W.J. Zheng, J.Z. Xiang, Z.G. Song, H. Feng, Y.L. Zhu, Acta Metall. Sin. (Engl. Lett.) 27, 313 (2014)

[9] Y.C. Zhu, W.D. Zeng, F. Feng, Y.S. Sun, Y.F. Han, Y.G. Zhou, Mater. Sci. Eng. A 528, 1757 (2011) 
[10] C.P. Chou, S.C. Wang, C.C. Chang, W.R. Wang, Acta Metall. Sin. (Engl. Lett.) 13, 606 (2000)

[11] D.X. Wen, Y.C. Lin, H.B. Li, X.M. Chen, J. Deng, L.T. Li, Mater. Sci. Eng. A 591, 183 (2014)

[12] D.G. He, Y.C. Lin, M.S. Chen, J. Chen, D.X. Wen, X.M. Chen, J. Alloys Compd. 649, 1075 (2015)

[13] Y.V.R.K. Prasad, K.P. Rao, S. Sasidhara, Hot Working Guide: A Compendium of Processing Maps (ASM International, Materials Park, 1997)

[14] S. Anbuselvan, S. Ramanathan, Trans. Nonferrous Met. Soc. China 21, 257 (2011)

[15] T. Zhong, K.P. Rao, Y.V.R.K. Prasad, M. Gupta, Mater. Sci. Eng. A 559, 773 (2013)

[16] S.Z. Zhu, T.J. Luo, T.A. Zhang, Y.S. Yang, Trans. Nonferrous Met. Soc. China 25, 3232 (2015)

[17] K.P. Rao, K. Suresh, Y.V.R.K. Prasad, N. Hort, K.U. Kainer, J. Mater. Sci. Technol. 30, 2699 (2016)

[18] Z.H. Zhou, Q.C. Fan, Z.H. Xia, A.G. Hao, W.H. Yang, W. Ji, H.Q. Cao, J. Mater. Sci. Technol. 33, 637 (2016)

[19] J. Liu, Z.S. Cui, C.X. Li, J. Mater. Process. Technol. 205, 497 (2008)

[20] A. Mkaddem, R. Bahloul, J. Mater. Process. Technol. 189, 441 (2007)

[21] H. Naceur, S. Ben-Elechi, J.L. Batoz, C. Knopf-Lenoir, Mater. Des. 29, 781 (2008)

[22] P. Li, Y.G. Ding, P.P. Yao, K.M. Xue, Chin. J. Nonferrous Met. 26, 1019 (2016). (in Chinese)

[23] Z.Y. Jin, Z.S. Cui, J. Mater. Sci. Technol. 26, 1063 (2010)

[24] H. Ziegler, Progress in Solid Mechanics (Wiley, New York, 1963), pp. 93-193
[25] Y.V.R.K. Prasad, Metall. Mater. Trans. A 27, 235 (1996)

[26] H.Z. Li, X.Y. Wei, J. Ouyang, J. Jiang, Y. Li, Trans. Nonferrous Met. Soc. China 23, 3180 (2013)

[27] S. Wang, L.G. Hou, J.R. Luo, J.S. Zhang, L.Z. Zhuang, J. Mater. Process. Technol. 225, 110 (2015)

[28] K. Kondo, T. Jitsunari, K. Ohga, Bull. JSME 28, 2442 (1985)

[29] Z.Y. Jin, N.N. Li, K. Yan, D.L. Wei, Z.S. Cui, Trans. Nonferrous Met. Soc. China 27, 2172 (2017)

[30] Y.L. Yang, G.Y. Chen, Q.M. Dong, J.K. Xi, J. Henan Univ. Sci. Technol. 2, 57 (1985)

[31] L. Wang, T.C. Lee, J. Mater. Process. Technol. 167, 447 (2005)

[32] M.M.A. Khan, L. Romoli, M. Fiaschi, G. Dini, F. Sarri, Int. J. Adv. Manuf. Technol. 62, 587 (2012)

[33] M.M.D. Zulkali, A.L. Ahmad, N.H. Norulakmal, Bioresour. Technol. 97, 21 (2006)

[34] B.J. Lv, J. Peng, D.W. Shi, A.T. Tang, F.S. Pan, Mater. Sci. Eng. A 560, 727 (2013)

[35] P.W. Flynn, J. Mote, J.E. Dorn, Trans. Met. Soc. 221, 1148 (1961)

[36] Y. Chino, K. Kimura, M. Mabuchi, Mater. Sci. Eng. A 486, 481 (2008)

[37] S. Spigarelli, O.A. Ruano, Mater. Sci. Eng. A 570, 135 (2013)

[38] Y.V.R.K. Prasad, K.P. Rao, Mater. Sci. Eng. A 432, 170 (2006)

[39] T. Obara, H. Yoshinga, S. Morozumi, Acta Metall. 21, 845 (1973)

[40] H. Zhou, Q.D. Wang, B. Ye, W. Guo, Mater. Sci. Eng. A 576, 101 (2013)

[41] O. Sivakesavam, Y.V.R.K. Prasad, Mater. Sci. Eng. A 362, 118 (2003) 